\title{
Characteristics of the Cold-Rolling Texture in a Multi-Layered Material Composed of SUS301 and SUS420J2 Steels
}

\author{
Long $\mathrm{Li}^{1}$, Fuxing Yin ${ }^{1}$, Yoshihisa Tanaka ${ }^{2}$, Satoshi Kishimoto ${ }^{2}$ and Kotobu Nagai ${ }^{1}$ \\ ${ }^{1}$ Exploratory Materials Research Laboratory for Reliability and Safety, National Institute for Materials Science, \\ Tsukuba 305-0047, Japan \\ ${ }^{2}$ Hybrid Materials Research Center, National Institute for Materials Science, Tsukuba 305-0047, Japan
}

\begin{abstract}
A multi-layered composite material composed of alternating SUS301 and SUS420J2 steels, prepared by hot-rolling bonding, shows a superior strength and ductility balance than the components. Few researches have been addressed on texture features of structural multi-layered materials during cold-rolling. In the present work, cold-rolling with three reductions $(20 \%, 40 \%$ and $65 \%)$ in thickness was conducted on both the two monolithic steels (SUS301 and SUS420J2) and the multi-layered material consisting of SUS301 and SUS420J2 components. Texture and microstructure development during the cold-rolling deformation in both the monolithic steels and multi-layered material were investigated by using EBSD technique. It was found that austenite phase in SUS301 component of the multi-layered material showed weaker $\langle 110\rangle / / \mathrm{ND}$ texture as compared to the monolithic SUS301 steel although the similar texture characteristics appeared in both conditions. On the other hand, the martensite phase in SUS420J2 component of the multi-layered material showed stronger $\{112\}\langle 110\rangle$ texture components than the $\langle 111\rangle / / \mathrm{ND}$ and $\langle 100\rangle / / \mathrm{ND}$ texture components that were dominant in the monolithic SUS420J2 steel. It is considered that the constraint condition and shear stress at component layer interfaces are significant for the formation of Brass component observed as the final stable orientation of austenite phase of the SUS301 steel in the multi-layered samples, and the formation of the $\{112\}\langle 110\rangle$ texture of martensite phase of the SUS420J 2 steel in the multi-layered samples during the cold-rolling deformation. [doi:10.2320/matertrans.MG200906]
\end{abstract}

(Received October 13, 2009; Accepted February 18, 2010; Published April 7, 2010)

Keywords: hot-rolling bonding, SUS301, SUS420J2, multi-layered material, cold-rolling, texture

\section{Introduction}

Multi-layered composite materials consisting of alternating metals or alloys have been developed to improve the mechanical properties including fracture toughness, fatigue behavior, impact behavior, wear, corrosion, and even provide the enhanced deformability for otherwise brittle materials. ${ }^{1)}$ Multi-layered materials that combine austenitic steels with high ductility and martensitic steels with high strength possess a good balance of high strength and ductility, as well as the good formability compared to the low ductility martensitic steel. ${ }^{2-4)}$ Recently, the uniform elongation of asquenched martensitic steel was increased from $6 \%$ to more than $50 \%$ level by the multi-layered structure design through bonding the martensitic steel sheets with the austenitic steel sheets, ${ }^{4)}$ which enhances the expectation to fabricate highstrength structural materials.

Texture plays an important role in the metal forming of sheet products. Deformation and annealing texture development in steels have been studied in details. ${ }^{5-10)}$ In cold-rolled SUS301 steel, it was found that the main texture component was characterized by $\{110\}\langle 112\rangle$ Brass, $\{110\}\langle 001\rangle$ Goss and $\{112\}\langle 111\rangle$ Copper components. $\left.{ }^{6}\right)$ In ferritic stainless steels and martensitic steels, $\alpha$-fiber and $\gamma$-fiber were observed to be the dominant texture components. ${ }^{8-10)}$ Although the mechanical properties of multi-layered materials have been extensively studied, ${ }^{1)}$ few reports have been addressed on the texture development of the structural multi-layered materials during cold-rolling and subsequent annealing. It is considered that the different mechanical properties of the components in composites will obviously affect the stress and strain states during rolling and further influence the crystallographic texture development in the component steels. ${ }^{11)} \mathrm{Up}$ to now, investigations on texture development in multi- layered materials are only focused on $\mathrm{Al}$ alloy during hotrolling bonding for structural applications ${ }^{11)}$ and functional materials such as multi-layered $\mathrm{Ni}$ base tapes in superconductor application, ${ }^{12)}$ sputter-deposited nano-scale $\mathrm{Cu} /$ $\mathrm{Nb}$ multi-layered thin films, ${ }^{13)}$ micro-scale $\mathrm{Cu} / \mathrm{Nb}$ composite ${ }^{14)}$ and $\mathrm{Mg} / \mathrm{Al}$ laminated composite fabricated by accumulative roll bonding. ${ }^{15)}$ In addition, comparative studies on texture development have not been addressed between monolithic and multi-layered materials, especially for structural steels.

In this study, the main objective is to investigate the microstructure and micro-texture development of multilayered composite materials during cold-rolling. A multilayered composite material consisting of 25 alternating layers of SUS301 austenitic and SUS420J2 martensitic steels bonded by hot-rolling was applied. Subsequent cold-rolling deformation on the monolithic and the multi-layered material was conducted with varied reductions $(20 \%, 40 \%$ and $65 \%)$, and microstructure and texture were studied using scanning electron microscopy equipped with electron back scattered diffraction (EBSD) technique.

\section{Experimental Procedures}

\subsection{Materials and processing}

The materials employed in this study is austenitic steel (SUS301), martensitic steel (SUS420J2) and a multi-layered composite material consisting of SUS301 and SUS420J2 steels. The monolithic SUS301 and SUS420J2, which were received as $1 \mathrm{~mm}$ thickness in the form of sheet, were subjected to heat treatment at $1273 \mathrm{~K}$ for $15 \mathrm{~min}$ to obtain a randomly oriented polycrystalline microstructure. The chemical composition of SUS301 and SUS420J2 steels is shown in Table 1. 
Table 1 Chemical composition of the component steels used (mass $\%$ ).

\begin{tabular}{ccccccccc}
\hline Material & $\mathrm{C}$ & $\mathrm{Si}$ & $\mathrm{Mn}$ & $\mathrm{P}$ & $\mathrm{S}$ & $\mathrm{Ni}$ & $\mathrm{Cr}$ & Bal. \\
\hline SUS301 & 0.10 & 0.66 & 0.68 & 0.027 & 0.003 & 7.05 & 17.04 & $\mathrm{Fe}$ \\
SUS420J2 & 0.34 & 0.49 & 0.57 & 0.035 & 0.004 & 0.12 & 13.21 & $\mathrm{Fe}$ \\
\hline
\end{tabular}

The multi-layered composite material (MLCM) is composed of 25 alternating layers of SUS301 and SUS420J2 steels (13 SUS301 and 12 SUS420J2 layers, 25LCM hereafter), which were produced by hot-rolling bonding to a final thickness of $3 \mathrm{~mm}$ with a total reduction of $88 \%$. SUS301 and SUS420J2 steels were initially cut in $125 \mathrm{~mm} \times 230 \mathrm{~mm}$ rectangular pieces, and then surface preparation, stacking and welding at the corner were conducted. The materials were kept at reheating temperature $1473 \mathrm{~K}$ for $30 \mathrm{~min}$ in argon atmosphere furnace. Then four-pass hot-rolling was carried out and hot-rolling temperature was approximately $1373 \mathrm{~K}$, $1373 \mathrm{~K}, 1273 \mathrm{~K}$ and $1243 \mathrm{~K}$, respectively. Subsequent annealing treatment was conducted at $1273 \mathrm{~K}$ for $2 \mathrm{~min}$ in order to obtain the randomly oriented microstructure. The average thickness of the SUS301 layers and SUS420J2 layers in the composites was about $122 \mu \mathrm{m}$.

Cold-rolling with three reductions $(20 \%, 40 \%$ and $65 \%)$ was conducted on both as-annealed monolithic and the multilayered material. The roll diameter and rolling speed were $120 \mathrm{~mm}$ and $5 \mathrm{~m} / \mathrm{min}$, respectively. In order to avoid the effect of shear strain on the microstructure and texture at the surface due to friction between the rolls and the work piece, only the normal direction (ND) section at the mid-thickness region of monolithic samples was focused in this work. In order to investigate the effect of interface between two components of multi-layered samples without considering the effects of surface friction between the rolls and the work piece, transverse direction (TD) section of multi-layered samples at the mid-thickness regions containing 7 layers were chosen as a comparison with the monolithic samples.

\subsection{Microstructure and texture characterization}

The samples were prepared by mechanically grinding and electrochemical polishing in a solution consisting of perchloric acid $\left(\mathrm{HClO}_{4}\right)$ and acetic acid (95:5) under $2 \mathrm{~A} / \mathrm{cm}^{2}$ at $10^{\circ} \mathrm{C}$ for microstructural analysis. The microstructure and micro-texture were investigated on ND section for the monolithic samples and TD section for the multilayered material, using a LEO-1550 field-emission scanning electron microscopy equipped with the TSL type automated electron backscattered diffraction (EBSD) system. Particular attention has been paid to the analysis of the matrix grain structures, grain boundary misorientation distribution and crystallographic textures. Acquisition of EBSD data was carried out with an acceleration voltage of $15 \mathrm{kV}$ and working distance of $15 \mathrm{~mm}$. The corresponding data processing was carried out using a Tex-SEM laboratories orientation imaging microscope (OIM) system. Orientation mapping was performed on a rectangular grid with a step size of $0.2 \mu \mathrm{m}$. Microstructure maps show the grains based on misorientation angle and texture maps illustrate the sharpness of crystallographic orientations as inverse pole figure (IPF) and orientation distribution function (ODF).
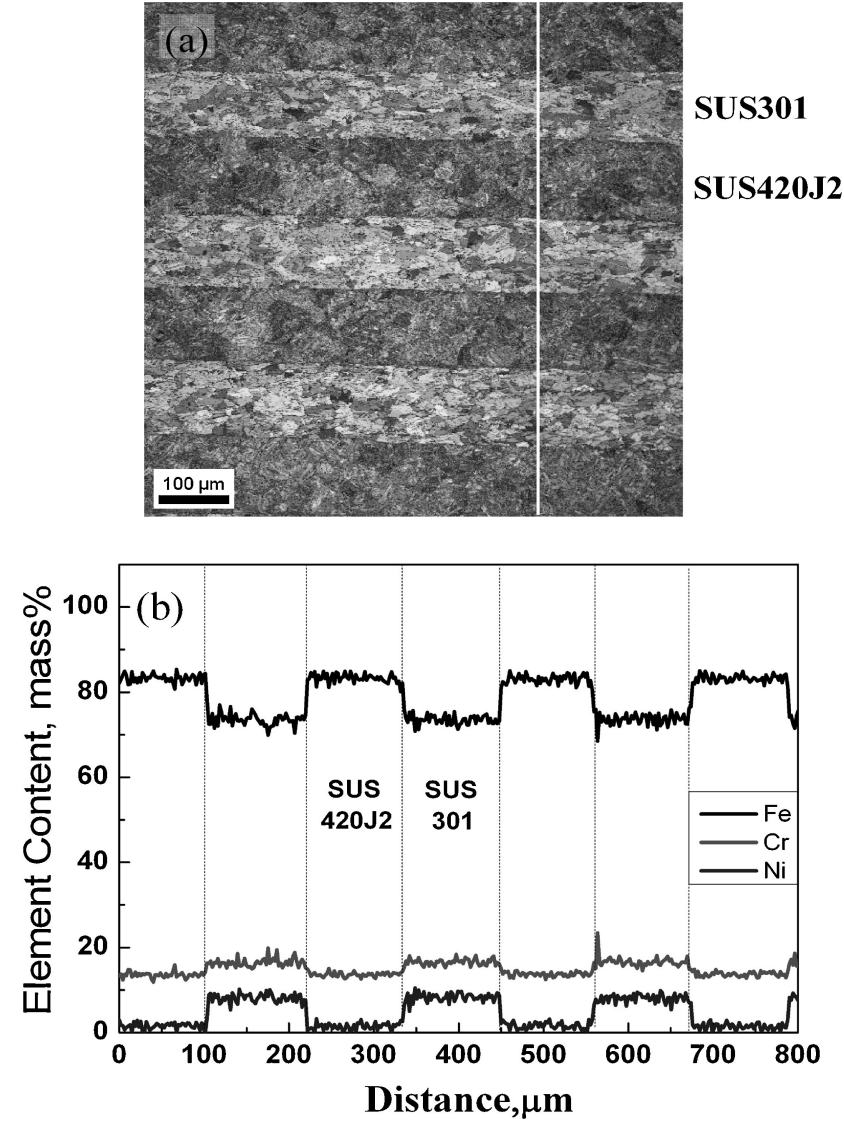

Fig. 1 EBSD mapping of TD section of the as-annealed multi-layered materials (a) and change in the concentration of main elements across the interfaces (b).

\section{Experimental Results}

\subsection{Microstructure of SUS301 and SUS420J2 steels in monolithic and multi-layered samples}

Figure 1 shows the EBSD microstructure of the 7 middle layers in the as-annealed multi-layered material, and the EDS (Energy Dispersive Spectroscopy) line scan results along the line shown in the EBSD mapping. The width of the Fe, Ni and $\mathrm{Cr}$ element diffusion layer at the interfaces is in the range of $4.0 \sim 6.0 \mu \mathrm{m}$, and the diffusion zone seems to be homogeneous in both thickness and length positions.

Figure 2 shows the austenite microstructure of the SUS301 steel at different cold-rolling reductions in both monolithic and multi-layered samples. The microstructural development during cold-rolling is shown in the EBSD mapping of Fig. 2(b)-(d) and Fig. 2(f)-(h), respectively for monolithic and multi-layered samples. The SEM results indicate that the as-annealed samples of monolithic and multi-layered materials before cold-rolling show an equiaxed grain microstructure on both TD and ND sections. The as-annealed materials possess an average grain size of $24 \mu \mathrm{m}$ and $12 \mu \mathrm{m}$ in monolithic and multi-layered samples, respectively, as illustrated in Fig. 2(a) and Fig. 2(e). With the increased cold-rolling reduction, the austenite microstructure seems to be elongated obviously parallel to the rolling direction as shown in Fig. 2(f)-(h) in SUS301 steels of the multi-layered samples. Additionally, the microstructure of SUS420J2 steels at different cold-rolling reductions in both monolithic and 


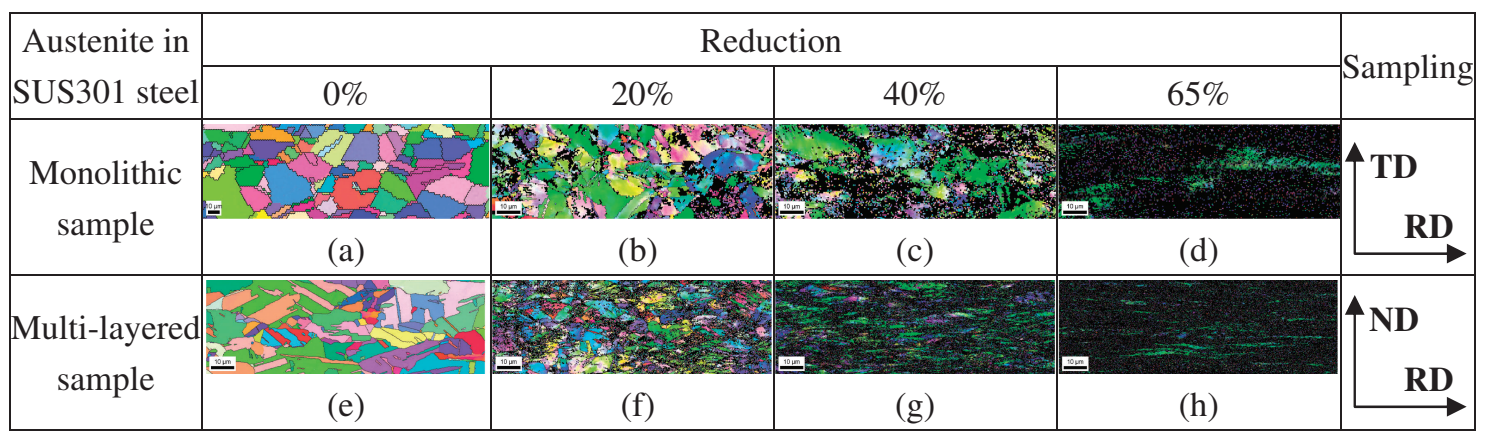

Fig. 2 EBSD mapping of austenite phase in SUS301 steel: (a)-(d) monolithic samples; (e)-(h) multi-layered samples.

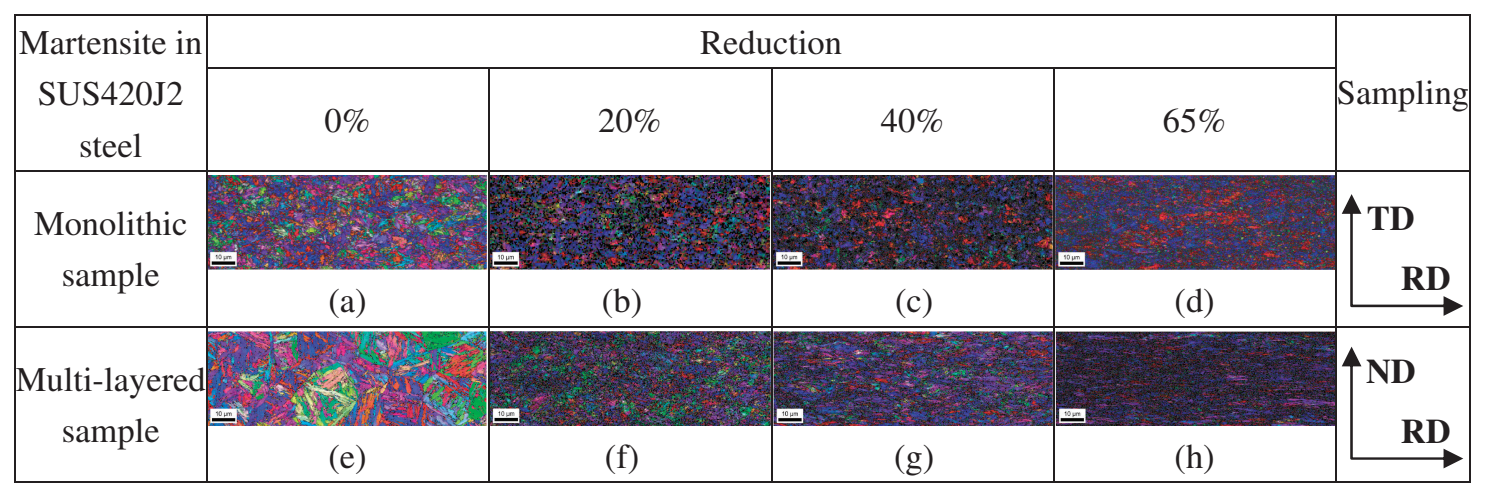

Fig. 3 EBSD mapping of martensite phase in SUS420J2 steel: (a)-(d) monolithic samples; (e)-(h) multi-layered samples.

multi-layered samples were shown in Fig. 3. Martensite plate can be observed to some extent in the as-annealed samples but it is difficult to distinguish the martensite plate of the samples at higher reduction than $20 \%$ due to cold-rolling deformation.

In the present study, the area ratio of martensite phase to all phases is used to denote the volume fraction of martensite phase, which can be directly calculated from OIM data in EBSD mapping by finding the number of crystal structure measurements and dividing it by the total number of measurements. Figure 4 shows the volume fraction of martensite phase in SUS301 steel, and Vickers hardness of SUS301 steel and SUS420J2 steel in monolithic and multilayered samples. It can be found that the volume fraction of strain-induced martensite phase in the SUS301 steel increases with the increase in rolling reduction in both monolithic and multi-layered samples, and the hardness of SUS301 steel also increases obviously with the increase in deformation.

It should be pointed out that the hardness of the monolithic SUS301 steel is lower than that of SUS301 in multi-layered sample at reductions less than $40 \%$ as shown in Fig. 4. The carbon diffusion from SUS420J2 to SUS301 layer in multilayered samples seems to be inevitable during hot-rolling bonding since the large difference in carbon content in the two component steels as shown in Table 1, which can be a major factor affecting the hardness of components of multilayered samples. From Fig. 4, it can be seen that the volume fraction of martensite in SUS301 of the LCM is slightly less than that in the monolithic sample at the rolling reduction of $65 \%$, which may be related to the higher stability of austenite

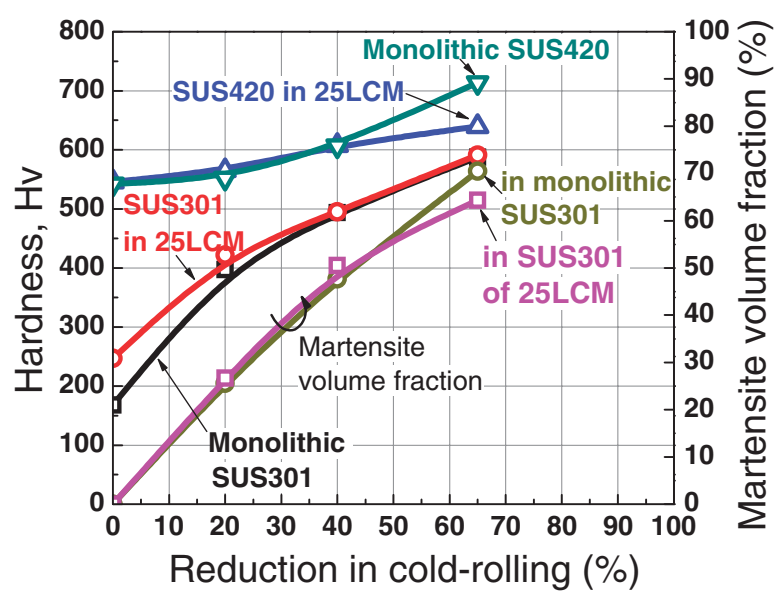

Fig. 4 Volume fraction of martensite phase in SUS301 steel and Vickers hardness of SUS301 steel and SUS420J2 steel as a function of cold-rolling reduction.

phase in SUS301 steel probably due to the high carbon content resulting from carbon diffusion, which relies on the precise carbon element analysis. The lower hardness of SUS420J2 steel in the multi-layered samples at the reduction of $65 \%$ than monolithic samples may be one of the evidences of carbon diffusion from SUS420J2 to SUS301 components. Lower volume fraction of strain-induced martensite but higher carbon content in SUS301 steel of the multi-layered sample lead to the similar hardness as compared with monolithic sample at $65 \%$ reduction (Fig. 4). In fact, the differences in hardness and volume fraction of strain-induced martensite of SUS301 steel between monolithic and multi- 

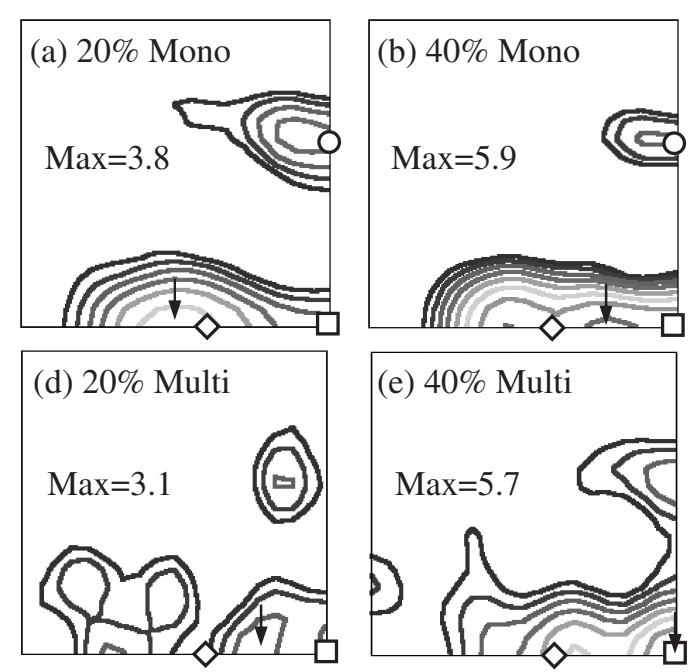
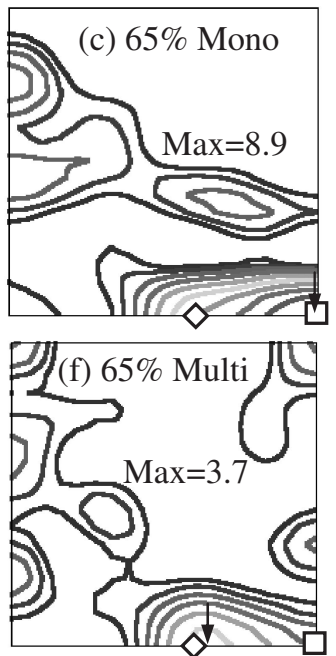

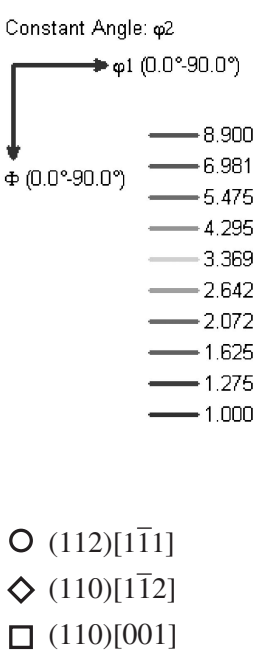

Fig. $5 \varphi_{2}=45^{\circ}$ sections in ODF of austenite phase in SUS301 steel at different reduction levels. Monolithic (Mono): (a) 20\%; (b) 40\%; (c) 65\%; Multi-layered (Multi): (d) 20\%; (e) 40\%; (f) 65\% (Maximum levels shown in the figures are depicted as an arrow head).

layered samples should be associated with component thickness, carbon diffusion width, hardness indentation size as well as cold-rolling reduction. More detailed work needs to be done in the future.

\subsection{Texture of austenite phase in SUS301 steel}

Orientation data are extracted from EBSD mapping using orientation distribution function (ODF) notation. Figure 5 shows the $\varphi_{2}=45^{\circ}$ section in the ODF of the austenite in SUS301 steel of the monolithic and multi-layered samples rolled to different reductions. During cold-rolling deformation, the crystal orientations of the austenite in monolithic SUS301 steel mainly concentrate along $\alpha$-fiber $\left(45^{\circ} \leq \varphi_{1} \leq\right.$ $90^{\circ}, \Phi=90^{\circ}, \varphi_{2}=45^{\circ}$ ). The $20 \%$ cold-rolling deformation leads to the formation of a texture characterized by texture components in monolithic samples: (110)[55̄7] $\left(\varphi_{1}=45^{\circ}\right.$, $\Phi=90^{\circ}$ ) that is $10^{\circ}$ rotated around ND from the exact (110)[11 2 ] Brass orientation $\left(\varphi_{1}=55^{\circ}, \Phi=90^{\circ}\right)$ as well as a weak Copper orientation (112) $[\overline{1} 11]\left(\varphi_{1}=90^{\circ}, \Phi=35^{\circ}\right)$. With increase in the rolling reduction to $40 \%$, Copper orientation becomes much weaker while the Goss orientation (110)[001] $\left(\varphi_{1}=90^{\circ}, \Phi=90^{\circ}\right)$ are observed clearly. By $65 \%$ rolling reduction, Copper orientation disappears and Brass orientation becomes weak while Goss orientation has developed obviously as shown in Fig. 5(a)-(c). Such a texture is a typical characteristic of as cold-rolled texture of austenitic steels. ${ }^{6}$ )

As shown in Fig. 5(d)-(f), the deformation textures measured for the austenite phase in the SUS301 layers of the multi-layered samples are found to be similar to those of the monolithic SUS301 steel cold-rolled to 40\%, although the component intensity is a little weaker than that in monolithic samples. When increasing the rolling reduction to $65 \%$, Brass orientation has developed obviously meanwhile Goss orientation becomes quite weak in the multi-layered sample, which shows an opposite tendency in the texture development as compared to the monolithic sample. The highest orientation density (maximal value of 8.9) is reached (Fig. 5(c)) at the Goss orientation in the monolithic sample, while that is only 3.7 at the Brass orientation in the multilayered sample (Fig. 5(f)). Although EBSD observation was made in two fields for higher than $40 \%$ cold-rolled samples, it should be pointed out that there are many unanalyzable points at reductions higher than $40 \%$ and the ODFs may be considered to be composed of local textures of analyzable parts with a small area fraction. Therefore, the orientation density may, to some extent, depend on the location and step size in EBSD analysis.

\subsection{Texture of martensite in SUS420J2 steel}

Figure 6 shows the $\varphi_{2}=45^{\circ}$ section in the ODF maps of martensite phase in SUS420J2 steel of both monolithic and multi-layered samples. The texture components are dominated by $\langle 111\rangle / / \mathrm{ND} \gamma$-fiber and $\langle 001\rangle / / \mathrm{ND}$ in monolithic sample as shown in Fig. 6(a)-(c). The major texture with maximum intensity about 4.6 are (111)[121] and (111)[1 $\overline{1} 2]$ at the rolling reduction of $65 \%$. However, texture components $\{112\}\langle 110\rangle$ at $\alpha$-fiber are observed and the intensity increase significantly with cold-rolling deformation from $20 \%$ to $40 \%$ reduction in the multi-layered sample as shown in Fig. 6(d)-(f). Additionally, the rotated Cube (001)[110] and (001)[1 10$]$ orientations, which are dominant components in monolithic sample, have not been observed in the multilayered samples when cold-rolled to $40 \%$, although a quite weak rotated Cube (001)[1 $1 \overline{1} 0]$ and (001)[110] can be observed in the multi-layered sample at $65 \%$ rolling reduction. At rolling reductions higher than 20\%, the development of the texture components seems to be much stronger in multi-layered sample than that in the monolithic sample. The ODF maximum reaches to 7.1 when $40 \%$ cold-rolling was conducted; nevertheless it then becomes weaker with the further increase of cold-rolling reduction to $65 \%$.

The maximum intensity development of those main texture components of the SUS420J2 steel in the ODFs, including the rotated Cube (001)[1 10$]\left(\varphi_{1}=0^{\circ}, \Phi=0^{\circ}\right.$, $\left.\varphi_{2}=45^{\circ}\right),(111)[01 \overline{1}]\left(\varphi_{1}=60^{\circ}, \Phi=55^{\circ}, \varphi_{2}=45^{\circ}\right)$ in $\gamma$-fiber components and (112)[110] $\left(\varphi_{1}=0^{\circ}, \Phi=35^{\circ}\right.$, 


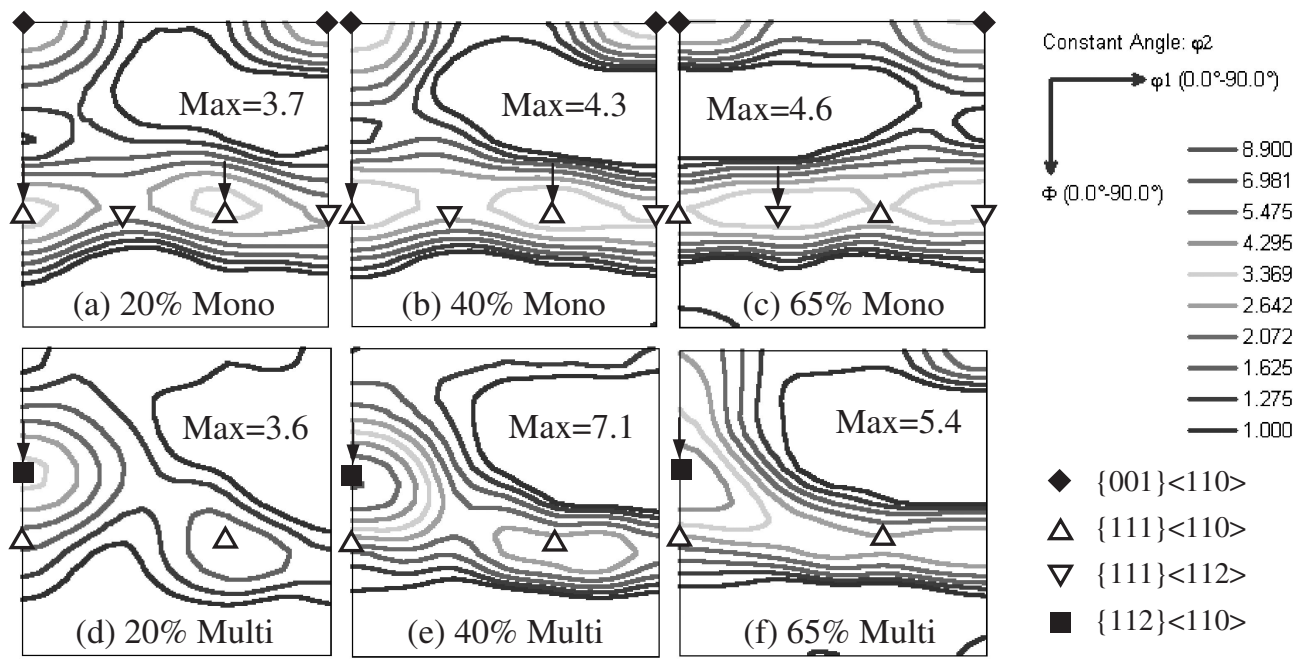

Fig. $6 \varphi_{2}=45^{\circ}$ sections in ODF of martensite phase in SUS420J2 steel at different reduction levels. Monolithic (Mono): (a) 20\%; (b) 40\%; (c) 65\%; Multi-layered (Multi): (d) 20\%; (e) 40\%; (f) 65\% (Maximum levels shown in the figures are depicted as an arrow head).
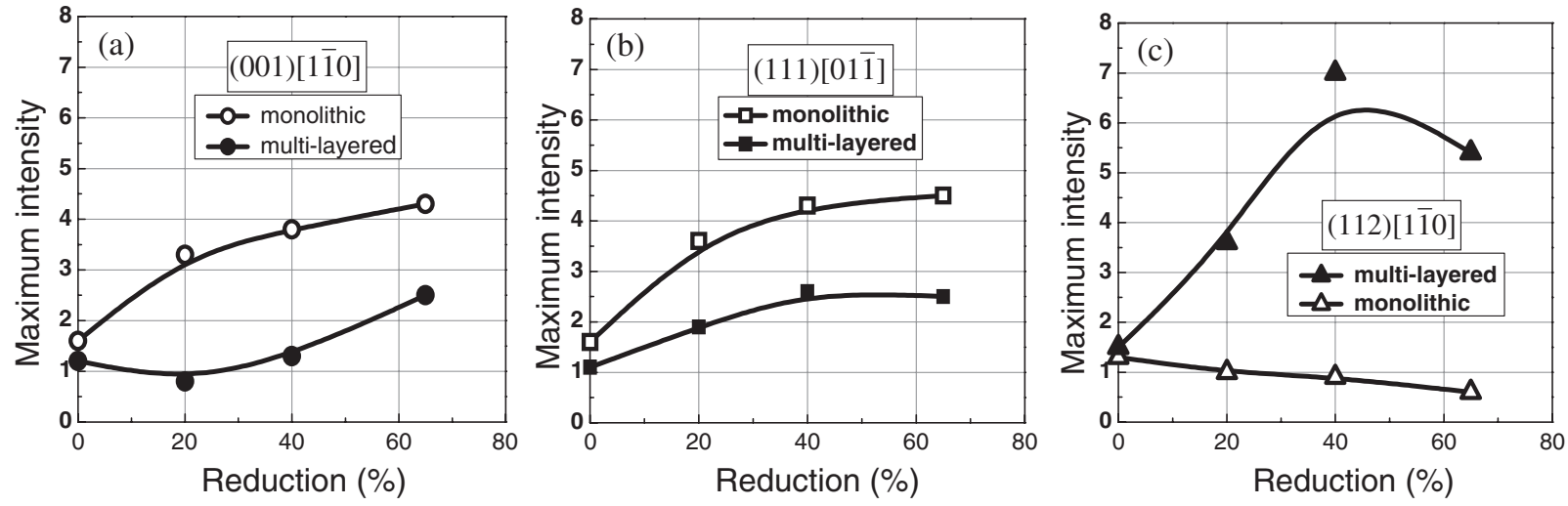

Fig. 7 Maximum intensity variation of (001)[110] (a), (111)[011̄] (b) and (112)[110] (c) of martensite phase in SUS420J2 steel as a function of cold-rolling reduction.

$\varphi_{2}=45^{\circ}$ ) are described in Fig. 7 as a function of cold-rolling reduction. It is found that the texture of as-annealed SUS420J2 steel remains very weak and the component intensity can be considered as random orientation in EBSD analysis. As shown in Fig. 7(a) and (b), the intensities of rotated Cube and $\gamma$-fiber components in monolithic samples keep increasing during the whole rolling stages and the maximum intensity is always higher than that in the multilayered sample. However, the (112)[1 $1 \overline{1} 0]$ texture, which has not been observed in the monolithic sample, becomes the dominant component in multi-layered sample (Fig. 7(c)). Additionally, it is interesting that the intensity of (112)[110] obviously increases up to peak at the $40 \%$ rolling reduction and then decreases in multi-layered samples as shown in Fig. 7(c).

\section{Discussion}

\subsection{Texture characters of austenite phase of the SUS301 steel}

The present results indicate that $\alpha$-fiber texture in the SUS301 steel, including two pronounced components: (110)[11̄2] Brass and (110)[001] Goss orientations, seems to be an inherent feature of austenite phase in the SUS301 steel deformed by cold-rolling in spite of monolithic and multi-layered sample as shown in Fig. 5. These orientations are typical ones of cold-rolling texture of fcc metals. ${ }^{6,7)}$ However, in the present study, the most important feature in texture is that the Goss component is dominant in monolithic sample (Fig. 5(c)), but Brass orientation becomes prominent in multi-layered samples when cold-rolled to $65 \%$ with reduction in thickness (Fig. 5(f)).

The texture development by cold-rolling deformation in fcc materials had been predicted based on Taylor model. ${ }^{16)}$ It was proposed that crystal orientations first concentrated along $\alpha$-fiber quickly and then rotated into copper orientation. Increased cold-rolling reduction would rotate the copper orientation towards Goss orientation ${ }^{7)}$ or further towards the Brass orientation. ${ }^{5,16)}$ It is well known that the development of deformation texture in metals and alloys depends strongly on stress and strain state during deformation.,11) H. G. Kang ${ }^{11)}$ simulated the stress and strain acted on the five-ply composites of $\mathrm{Al} /$ stainless steel during roll-cladding by finite element method, and the results revealed that shear stress formed at the interface between soft component and hard component, leading to microstructural distortions and shear 
textures. In the case of monolithic sample, the rolling deformation can be considered as plane strain compression $^{17,18)}$ and almost no shear stress was introduced since the ND section at the mid-thickness region was measured in the present work. Thus the texture of austenite phase of the SUS301 steel in monolithic sample may be considered as the result of plane strain deformation without shear stress. But for the cold-rolled multi-layered samples, the harder SUS420J2 steel may act like an expansion by the work-roll with large diameter; therefore, compared with monolithic samples, the different texture characters of austenite phase of the SUS301 steel in multi-layered samples is mainly attributed to different stress states caused by shear stress at the interface between components.

Actually, during cold-rolling deformation of SUS301 steel strip, the following processes proceed: deformation of austenite, strain-induced transformation of austenite into martensite and deformation of martensite. ${ }^{19)}$ Therefore, the texture development in SUS301 steel of multi-layered materials is a complicated and multifactor-controlled process, such as component thickness, interface constraint and stress state. The $65 \%$ reduction in thickness is not heavy rolling, and since a large part of austenite phase transforms into martensite, the retained austenite probably has Brass orientation. Therefore Brass orientation may be not necessarily finally stable in cold-rolling deformation of multilayered samples, although it is well known that for monolithic samples the final stable orientation by cold-rolling is Brass orientation in austenite phase such as for SUS301.6,7)

\subsection{Texture development of SUS420J2 steel in the cold- rolled materials}

The texture of monolithic SUS420J2 sample is composed of a pronounced and rather homogeneous $\gamma$-fiber $\langle 111\rangle / / \mathrm{ND}$ with maximum values near (111)[1ㅣㅣ $\left(\varphi_{1}=0^{\circ}, \Phi=55^{\circ}\right)$ and (111)[1 $\overline{1} 2]\left(\varphi_{1}=90^{\circ}, \Phi=55^{\circ}\right)$ and an incomplete $\alpha$ fiber with strong rolling components near (001)[110] and (111)[1 $1 \overline{1} 0]$. The texture of multi-layered samples show a $\gamma$ fiber accompanied by the (111) $[\overline{1} \overline{1} 2]\left(\varphi_{1}=90^{\circ}, \Phi=55^{\circ}\right)$ and (112)[1] 10$] \quad\left(\varphi_{1}=0^{\circ}, \quad \Phi=35^{\circ}\right)$ component which spreads out towards the (001)[1 $\overline{10}]$ orientation. The coldrolling textures in monolithic SUS420J2 samples are weaker and the texture becomes less sensitive to the cold-rolling deformation although the maximum intensity gradually increases (Fig. 7(a)-(c)). These results are in general similar to the predictions by means of various Taylor type models. ${ }^{5,8)}$ However, the most striking result of the present cold-rolling textures analysis is the fact that the strong (112)[110] component is observed in multi-layered samples, which increases and again decreases with increasing cold-rolling reduction as shown in Fig. 6(d)-(f) and Fig. 7(c).

During cold-rolling of the multi-layered materials, there is an identical compressive stress $\sigma_{3}$ induced by the rolling load in both components SUS301 and SUS420J2. Under the assumption that both components obey Tresca's yield criterion, if SUS301 steel and SUS420J2 steel in multilayered materials have shear yield stresses $k_{\mathrm{a}}$ and $k_{\mathrm{b}}$, respectively, then in order to sustain the same throughthickness normal stress $\sigma_{3}$ in both components, longitudinal stress $\sigma_{1}$ is induced as the following equation: ${ }^{17)}$

$$
\sigma_{1}^{a}-\sigma_{1}^{b}=2\left(k_{a}-k_{b}\right)
$$

where $\sigma_{1}^{a}$ and $\sigma_{1}^{b}$ is the longitudinal stress of SUS301 layer and SUS420J2 layer, respectively. In generating these different stresses, a shear stress $\tau$ must develop at the interface. ${ }^{18)}$ From the hardness of the SUS301 and SUS420J2 steel in multi-layered samples as a function of cold-rolling reduction (Fig. 4), it can be found that the hardness between SUS301 and SUS420J2 steel of multi-layered sample becomes close to each other with the increase in cold-rolling reduction as shown in Fig. 4. To some extent, it means that flow stress difference between two components becomes smaller and smaller, and corresponding longitudinal stress gap would become small. Therefore, according to the eq. (1), the shear stress developed at the interface becomes low with increasing cold-rolling reduction. The combination of longitudinal stress $\sigma_{1}$, compressive stress $\sigma_{3}$, and shear stress $\tau$ governs the stress state and further influences the texture development during cold-rolling deformation. This may be the main reason why the component intensity in multilayered samples shows a peak at $40 \%$ reduction for (112)[110] component in SUS420J2 steel of multi-layered samples as shown in Fig. 7(c). In other words, the texture type and intensity are controlled by both percent reductions in thickness and shear stress level due to the flow stress difference between two components.

In the case of bcc ferrite stainless steel, texture (111)[1피 can rotate to $(112)[1 \overline{1} 0]$ by normal slip with the increase in deformation according to M. Y. Huh's studies. ${ }^{8)}$ The (111)[1 10 ] orientation is closely related to the (112)[1 $\overline{10}]$ orientation by a $20^{\circ}$ rotation around $\langle 110\rangle / / \mathrm{RD}$ axis. In other words, it is very possible that the characteristic (112)[1 $\overline{1} 0]$ in multi-layered samples as shown in Fig. 6(d)-(f) comes from the rotation of (111)[1 $\overline{1} 0$ ] orientation and consequently results in the weakened $\gamma$-fiber orientation.

It has been well known that the mechanical properties in metals and alloys depend strongly on their texture. Primary processing such as cold rolling generally gives rise to a strong texture $\{112\}\langle 110\rangle$ in SUS420J2 steel of multi-layered samples rather than $\langle 111\rangle / / \mathrm{ND}$ and $\langle 100\rangle / / \mathrm{ND}$ fiber textures that are dominant in the monolithic SUS420J2 steel. Therefore, the tensile properties of the multi-layered materials would be obviously different from that achieved only by mixture law of monolithic SUS301 and SUS420J2 steel, which should be the focus of future research.

\section{Conclusions}

(1) The Goss and Brass texture components of austenite in the SUS301 layer of the multi-layered material are found to be much weaker than those in the monolithic SUS301 steel although the deformation texture appears to be similar when cold-rolled to $40 \%$ in reduction. By $65 \%$ cold-rolling reduction, Goss orientation would become dominant in monolithic samples but Brass orientation has obviously developed in the multilayered sample. However, textures in multi-layered samples would show the statistically biased orientation distribution since there are many unanalyzable points at reductions higher than $40 \%$. 
(2) The SUS420J2 layer in the multi-layered material shows the strong $\{112\}\langle 110\rangle$ texture rather than the $\langle 111\rangle / / \mathrm{ND}$ and $\langle 100\rangle / / \mathrm{ND}$ fiber textures that are dominant in the monolithic SUS420J2 steel. With increasing rolling reduction, the intensity of the (112)[110] component obviously increases to show a peak at the $40 \%$ rolling reduction and then decreases in the multi-layered sample.

(3) The texture component and intensity in SUS301 and SUS420J2 steel of multi-layered materials may be attributed to the combination of longitudinal stress $\sigma_{1}$, compressive stress $\sigma_{3}$, and shear stress $\tau$ developed at the interface between components.

\section{Acknowledgment}

This study was conducted as part of the LISM (LayerIntegrated Steels and Metals) Project funded by the Ministry of Education, Culture, Sports, Science and Technology of Japan.

\section{REFERENCES}

1) D. R. Lesuer, C. K. Syn, O. D. Sherby, J. Wadsworth, J. J. Lewandowski and W. H. Hunt, Jr.: Int. Mat. Rev. 41 (1996) 169-197.
2) J. Inoue, S. Nambu, Y. Ishimoto and T. Koseki: Scr. Mater. 59 (2008) 1055-1058.

3) S. Nambu, M. Michiuchi, J. Inoue and T. Koseki: Compos. Sci. Technol. 69 (2009) 1936-1941.

4) S. Nambu, M. Michiuchi, Y. Ishimoto, K. Asakura, J. Inoue and T. Koseki: Scr. Mater. 60 (2009) 221-224.

5) D. Raabe: Acta Mater. 45 (1997) 1137-1151.

6) H. Abreu, S. Carvalho and P. Neto: Mater. Res. 10 (2007) 359-366.

7) J. Łuksza, M. Ruminski, W. Ratuszek and M. Blicharski: J. Mater. Process. Technol. 177 (2006) 555-560.

8) M. Y. Huh and O. Engler: Mater. Sci. Eng. A 308 (2001) 74-87.

9) H. Yan, H. Bi, X. Li and Z. Xu: J. Mater. Process. Technol. 209 (2009) 2627-2631.

10) C. Ghosh, A. Haldar, P. Ghosh and R. K. Ray: ISIJ Int. 48 (2008) 16261634.

11) H. G. Kang, J. K. Kim, M. Y. Huh and O. Engler: Mater. Sci. Eng. A 452-453 (2007) 347-358.

12) P. P. Bhattacharjee, R. K. Ray and A. Upadhyaya: Mater. Sci. Eng. A 488 (2008) 84-91.

13) P. M. Anderson, J. F. Bingert, A. Misra and J. P. Hirth: Acta Mater. 51 (2003) 6059-6075.

14) S. C. V. Lim and A. D. Rollett: Mater. Sci. Eng. A 520 (2009) 189-196.

15) H. Chang, M. Y. Zheng, W. M. Gan, K. Wu, E. Maawadc and H. G. Brokmeier: Scr. Mater. 61 (2009) 717-720.

16) J. Hirsch and K. Lucke: Acta Metall. 36 (1988) 2863-2882.

17) I. T. Ferguson and B. Derby: Mater. Sci. Technol. 14 (1998) 510517.

18) S. L. Semiatin and H. R. Piehler: Metall. Trans. A 10 (1979) 97-107.

19) V. I. Yushkov, R. A. Adamescu, Y. S. Machnev, T. M. Gapeka and P. V. Geld: Mater. Sci. Eng. A 64 (1984) 157-169. 